\title{
Governança transnacional para a regulação de alimentos orgânicos: o caso da IFOAM.
}

\section{Resumo:}

Clara Ribeiro Camargo*

Alimento orgânico é aquele alimento que respeita o meio-ambiente, garantindo a viabilidade econômica dos produtores, o respeito aos direitos trabalhistas, o não uso de agrotóxicos e a saúde dos consumidores, ou seja, possui características que não podem ser verificadas por meio dos sentidos. Assim, foi necessário criar mecanismos de avaliação da conformidade a fim de reduzir as assimetrias de informação entre produtores e consumidores. Em nível internacional, a primeira organização a criar princípios aplicáveis a toda sociedade foi a IFOAM - Federação Internacional dos Movimentos da Agricultura Orgânica. A pergunta que guia este artigo é: como a IFOAM garante o compliance de seus membros, ou seja, o cumprimento das normas, se a rede global de produção e consumo de orgânicos possui tantas assimetrias entre os atores do Norte e do Sul? A hipótese deste trabalho é a de que como os maiores mercados de produtos orgânicos são os países desenvolvidos e estes exigem a certificação por auditoria de terceira parte com base na IFOAM, os princípios desta organização tornaram-se referência para o comércio internacional de orgânicos, em especial para a importação europeia, funcionando como uma espécie de barreira comercial aos mercados europeus, o que torna garantido o compliance das organizações de produtores e certificadoras em nível internacional.

Palavras chave: agricultura orgânica, certificação, governança internacional.

\section{Abstract:}

Organic food is that food which respects the environment, assuring economic sustainability to the farmers, respect to worker's rights, the non-use of agro-chemicals and consumer's health, in other words, its features can't be verified through the senses. This way, it was necessary to develop conformity assessment tools aiming to reduce information asymmetries between producers and consumers. Internationally, the first organization which created principles and norms applicable all around the world was IFOAM - International Federation of Organic Agricultures Movements. The question that guides this article is: how IFOAM assures compliance from its membership whether the organic global network of production and consumption is so asymmetric considering Northern and Southern actors? My supposition is that as the biggest organic markets are developed countries and they require third-party auditing certification based on IFOAM, its principles became reference to organic food international trade, especially to European importation, working as a trade barrier at

\footnotetext{
* Mestranda em Ciência Ambiental com graduação em Relações Internacionais, e-mail: clara.camargo@usp.br
}

Latitude, vol. 5, n², pp.31-48, 2011

DOI: https://doi.org/10.28998/2179-5428.20110203 


\section{Governança transnacional para a regulação de alimentos orgânicos: $O$ caso da IFOAM.}

European markets, what assures compliance from farmer's organizations and certifying agencies.

Key Words: Organic agriculture, certification, international governance.

\section{Apresentação}

O mercado de produtos orgânicos teve um expressivo crescimento na última década, de acordo com a IFOAM (International Federation of Organic Agriculture Movements). Em 1999, este mercado movimentava 15,2 bilhões de dólares e em 2010, passou a 58,1 bilhões, crescimento relativo de $389 \%^{1}$. A maior parte da demanda por produtos com atributos de sustentabilidade ambiental e social, bem como de saúde, vem dos países desenvolvidos. Os maiores mercados de alimentos orgânicos estão nos Estados Unidos, Alemanha e França, que movimentam 26,7; 8,4 e 4,7 bilhões de dólares cada, respectivamente. Por outro lado, verifica-se que a maior parte da produção está concentrada nos países em desenvolvimento, como Índia, Uganda e México de onde tem origem o maior número de produtores. A Índia lidera o ranking com 677.257 produtores certificados, seguida da Uganda com 187.893, e México com $128.826^{2}$. Os gráficos abaixo demonstram estes dados.

Gráfico 1. O mercado de orgânicos em bilhões de dólares de 1999 a 2010.

\footnotetext{
${ }^{1}$ Todos estes dados foram acessados no relatório anual de atividades da IFOAM, disponível em $<$ http://ifoam.org/public/Annual\%20Report/IFOAM Annual Report 2011 web.pdf $>$; último acesso em $2408 / 2012$

2 Idem
} 


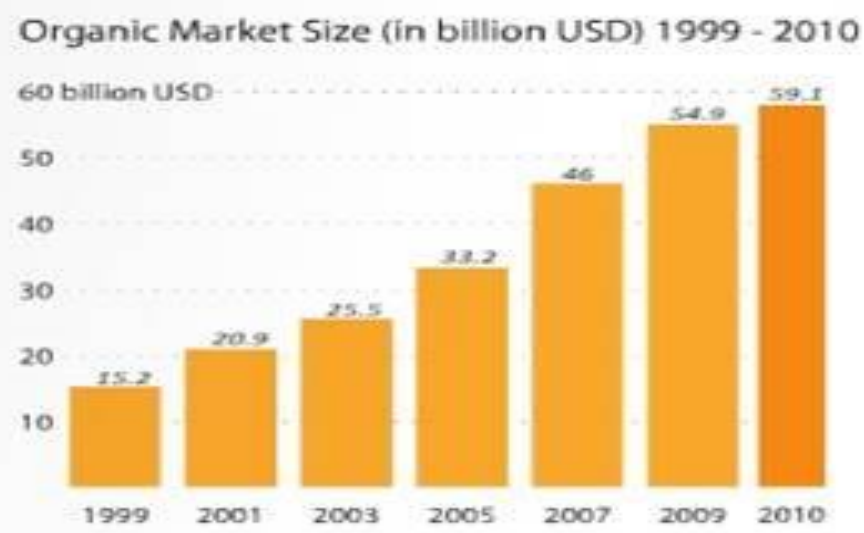

Fonte: The World of Organic Agriculture 2012, IFOAM and FiBL. Disponível em http://www.organic-world.net/yearbook-2012.html, último acesso em 06/11/2012

Gráfico 2. Produtores orgânicos no mundo (em milhões)

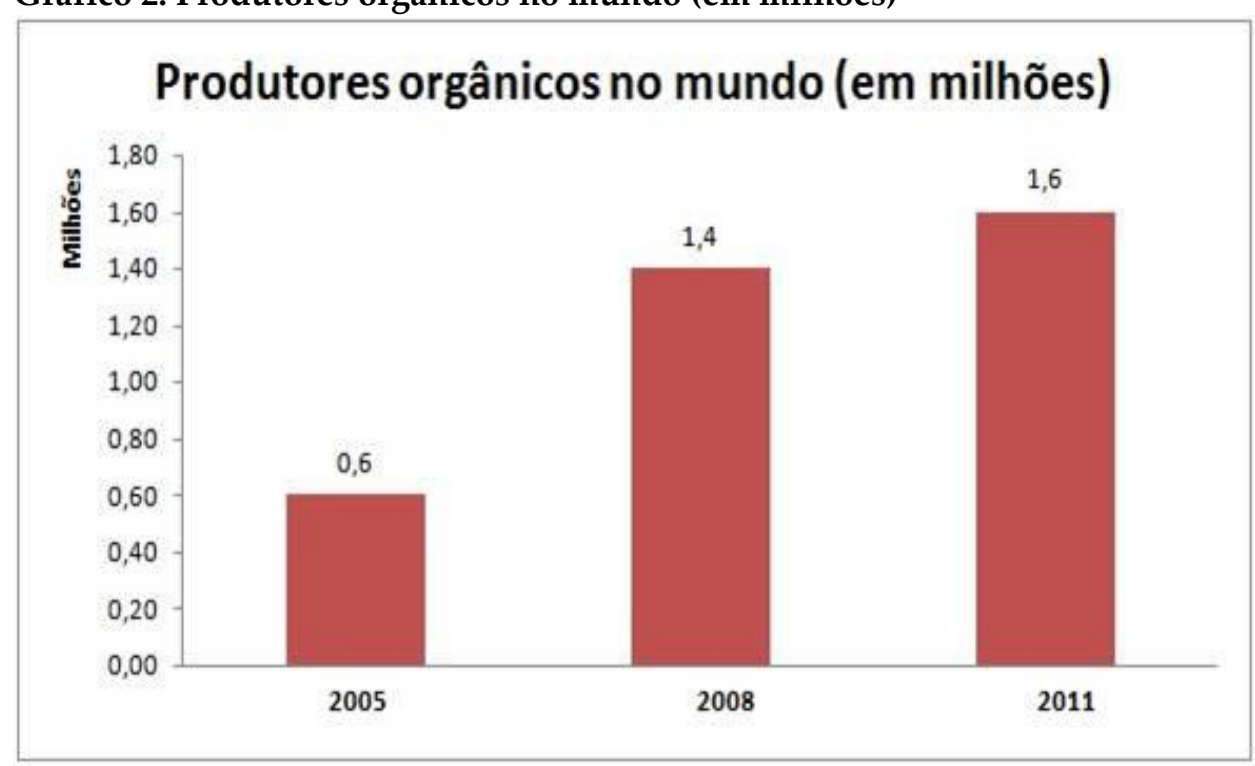


Governança transnacional para a regulação de alimentos orgânicos: $\mathrm{O}$ caso da IFOAM.

Fonte: The World of Organic Agriculture 2012, IFOAM and FiBL. Disponível em http://www.organic-world.net/yearbook-2012.html, último acesso em 06/1/2012Tabela 1. Indicadores da Agricultura Orgânica

\begin{tabular}{|c|c|c|}
\hline \multicolumn{3}{|c|}{ Números globais da Agricultura Orgânica } \\
\hline Indicador & Total Global & Países líderes \\
\hline $\begin{array}{l}\text { Terras agricolas } \\
\text { orgânicas }\end{array}$ & 37 milhões hectares & $\begin{array}{l}\text { Austrália (12 mi), Argentina } \\
(4.2 \mathrm{mi}) \text {, EUA (1.9 mi) }\end{array}$ \\
\hline Produtores & 1,6 milhões & $\begin{array}{l}\text { India }(677.257), \text { Uganda } \\
(187.893), \text { Mexico }(128.826)\end{array}$ \\
\hline $\begin{array}{l}\text { Números do mercado } \\
\text { de orgânicos }\end{array}$ & $\begin{array}{c}\$ \text { US 59,1 bi }(2009: \\
54,9 ; 2008: 50,9 ; 1999: \\
15,2)\end{array}$ & $\begin{array}{l}\text { EUA (\$US } 26,7 \text { bi.), Alemanha } \\
(8,4) \text {, France }(4,7)\end{array}$ \\
\hline $\begin{array}{l}\text { Consumo de orgânicos } \\
\text { per capta por ano }\end{array}$ & US\$ 8,6 (2009:8) & $\begin{array}{l}\text { Suíça (US\$ 213), Dinamarca } \\
\text { (198), Luxemburgo (177) }\end{array}$ \\
\hline $\begin{array}{l}\text { Número de afiliados à } \\
\text { IFOAM }\end{array}$ & $\begin{array}{c}870(2010: 757 ; 2008: \\
734 ; 2000: 606)\end{array}$ & $\begin{array}{l}\text { Alemanha }(105) \text {, Índia }(50) \text {, } \\
\text { China (41), Coreia do Sul(39), } \\
\text { EUA (39) }\end{array}$ \\
\hline
\end{tabular}

Fonte: The World of Organic Agriculture 2012, IFOAM and FiBL. Disponível em http://www.organic-world.net/yearbook-2012.html, último acesso em 06/1/2012

De acordo com estes dados, explicita-se que este mercado é global e possui desafios de regulação, o que explica a existência de uma federação responsável por criar os princípios, critérios e indicadores da agricultura orgânica. Este artigo se debruça sobre a estrutura de governança da IFOAM, caracterizada por ser uma organização transnacional que regula uma rede internacional de produtores, distribuidores, varejistas, e instituições certificadoras de produtos orgânicos. Para explicar este conceito, baseio-me no termo defendido por Laura Reynolds "rede de commodities" do setor agro alimentar que pode ser entendido como uma abordagem mais ampla que relaciona os links da produção, distribuição e consumo com a existência de instituições e relações de poder, ou seja, a influência de questões políticas 
e sociais, para compreender a atuação de atores e instituições na construção, manutenção e transformação das redes de orgânicos. De acordo com a autora,

"This approach follows the lead of commodity chain research in analyzing global commodity flows and firm relations linking production, distribution, and consumption. Yet it responds to recent calls for a more nuanced analysis of the institutions and relations of power, emphasizing the role of social and political, as well as economic, actors and actions in constructing, maintaining, and potentially transforming organic networks". (REYNOLDS, 2004)

Assim, pretendo analisar como a IFOAM garante o compliance de seus membros e implementa os seus princípios ao redor do mundo, considerando a existência de uma rede de produção, distribuição e consumo global de alimentos orgânicos com uma grande diversidade de atores. Verifica-se, assim, que as organizações de produtores, distribuidores, consumidores membros e certificadoras credenciadas da IFOAM aderem às normas estabelecidas pela federação, pois estas garantem acesso aos grandes mercados, principalmente da Europa. O conceito de compliance que utilizo é aquele desenvolvido por Miles Kahler, que segundo este autor, é questão chave para compreender a existência de esferas de autoridade governamentais ou não - eficazes no alcance de suas metas. Para ele, o compliance pode ser por coerção, mas também pode resultar de hábitos institucionalizados, da redefinição de interesses, da interdependência complexa, de compromissos normativos e de capacitação. Em outras palavras, o compliance pode ser intencional ou não, consciente ou subconsciente, imediata ou indecisa, o resultado de um conjunto de dinâmicas interativas. A sua efetividade depende exclusivamente das relações entre aqueles que presidem e aqueles que aderem.

\section{O Argumento}

O objetivo geral do trabalho é analisar os mecanismos privados de governança da IFOAM, com foco nos desafios de compliance e enforcement que esta organização possui em nível internacional, uma vez que reúne atores das redes de commodities globais, com interesses diversos e conflitantes.

A pergunta que guia este artigo é: como a IFOAM garante o compliance de seus membros se a rede global de produção e consumo de orgânicos possui tantas assimetrias entre os atores do Norte e do Sul?

A hipótese deste trabalho é a de que como os maiores mercados de produtos orgânicos, que são majoritariamente, os países desenvolvidos, exigem a certificação por auditoria de terceira parte independente e a IFOAM possui um sistema de garantia de alimentos orgânicos amplamente reconhecido ao redor do mundo, ela se tornou referência para o comércio internacional de orgânicos, em especial para a importação 


\section{Governança transnacional para a regulação de alimentos orgânicos: $\mathrm{O}$ caso da IFOAM.}

europeia, garantindo com isso o compliance das organizações de produtores e certificadoras e implementando os seus princípios em nível internacional. Sabe-se que a certificação é um mecanismo que reduz as assimetrias de informação e, com isso, os custos de transação. Assim, a existência da certificação é em si uma garantia de compliance e de monitoramento dos princípios construídos ao longo do tempo e verificados por terceira parte. O sistema de garantia via auditoria também diminui os custos de enforcement, ou seja, de implementação das regras por parte do produtor, com menor margem de não conformidade com os critérios e princípios estabelecidos pela organização.

A análise será feita a partir do foco e da especificidade da IFOAM cujo objeto é a agricultura orgânica, com um resgate histórico de como a organização surgiu, quais eram as demandas da sociedade em relação a este tipo de produto e como elas vem sendo incorporadas ao mercado, seguida de uma explicação sobre o contexto da insustentabilidade da agricultura industrial e como a Agricultura Orgânica pode solucionar alguns destes problemas advindos da cadeia produtiva de bens que são comercializados em nível global e, portanto, seguem a lógica da competitividade e do menor preço.

Em seguida, será feita uma análise institucional de como se dá o enforcement, o compliance e o monitoramento dos princípios, critérios e indicadores que devem estar contidos no processo produtivo certificado como alimento orgânico por uma instituição credenciada pela IFOAM. Neste momento, será discutido se a IFOAM garante legitimidade e autoridade nesta questão e para todos os atores envolvidos, sejam eles dos países desenvolvidos, sejam dos países em desenvolvimento.

\section{Abordagens Teóricas}

Muitos autores como Benjamin Cashore, Gary Gereffi \& Frederick Mayer, Thomas Hale \& David Held e Abbott\&Snidal, nos últimos anos, vem observando e escrevendo sobre novas estruturas de regulação de atividades econômicas e de governança na sociedade, em especial nas relações transnacionais. De acordo com Benjamin Cashore, está emergindo um novo tipo de governança não governamental através de incentivos de mercado, cujo propósito é desenvolver e implementar práticas ambiental e socialmente mais responsáveis. Ela é uma forma de regulação contrária à governança tradicional estatal e se volta às cadeias de valor para criar incentivos e forçar as empresas a aderir voluntariamente às regras e normas.

Estas formas de governança vêm ganhando força na resolução de problemas relacionados a Direitos Humanos, Meio-Ambiente, regulação financeira, entre outros, e pode ser compreendida como uma ampliação da arena de atuação dos atores não estatais, em que o Estado nacional delega autoridade à determinada organização ou a uma rede de organizações que possa solucionar determinado problema. Outras abordagens sugerem que devido à ausência de regulação pública, organizações e redes vem se organizando para resolver problemas oriundos da coordenação de cadeias produtivas, inserindo a responsabilidade social e ambiental nestes processos a fim de 
evitar uma má reputação de empresas e garantir o direito dos consumidores à informação.

Para Risse Kapen (1999), relações transnacionais são interações regulares para além das fronteiras nacionais, que tem pelo menos um agente não estatal e não opera para um governo nacional ou organização internacional. Os atores mais freqüentes na arena transnacional são ONGs, empresas multinacionais e comunidades epistêmicas (cientistas).

Esses atores transnacionais, de acordo com Held \& Hale (2011),

"provide technical expertise (Haas, 1991), set agendas (Betsill and Corell, 2008), monitor compliance (Keck and Sikkink, 1998) lobby decision makers (Mazey and Richardson, 2006), make regulatory decisions (Buthe, 2009) and even enforce them, by naming and shaming (Keck and Sikkink 1998; Hale, 2008b)

O conceito de rede de commodity global desenvolvido por Gereffi (2010) e bastante utilizado por Laura Reynolds é importante para a compreensão da regulamentação de alimentos em nível global e também se enquadra na explicação de regulação dos alimentos orgânicos. Para estes autores, a economia global está cada vez mais organizada em redes de produção internacional, onde a liderança das corporações está geralmente localizada nos países desenvolvidos, mas controlam uma extensão significativa de produção de fornecedores que operam em menor escala nos países em desenvolvimento. Também conhecida por diferentes conceitos como cadeia de commodity global, cadeia de valor global e redes de produção global, essa nova organização industrial permitiu à produção ser coordenada em escalas transnacionais, mas com muito mais flexibilidade do que o modelo antigo de propriedade das corporações multinacionais.

Esta abordagem permite explicar o surgimento da governança transnacional privada que, de acordo com estes autores, se dá como resposta à ausência de regulação pública, seja por parte dos Estados, seja por parte das organizações internacionais. É interessante notar que esta abordagem reconhece que as estruturas da governança industrial estabelecidas por empresas para manejar a sua cadeia de suprimentos poderia também alavancar objetivos sociais e ambientais. Os primeiros códigos de conduta das empresas eram feitos por elas próprias e tinham por objetivo monitorar a cadeia de valor. Porém, como os problemas relacionados a trabalho e meio-ambiente continuavam existindo na globalização da produção, abriu-se o campo de códigos de conduta para um modelo mais avançado, envolvendo parcerias entre empresas e ONGs. Esses atores passaram a identificar os problemas, fazer campanhas de denúncia contra violações trabalhistas e ambientais e ainda se propunham a desenvolver projetos e alternativas de mercado para resolvê-los. 


\section{Governança transnacional para a regulação de alimentos orgânicos: $\mathrm{O}$ caso da IFOAM.}

Com o objetivo de explicar estes fenômenos e criar uma teoria capaz de sustentar a existência de cooperação internacional através de redes de organizações transnacionais que regulam as cadeias de commodity sem os Estados (e as OIs), Gereffi \& Mayer (1994) desenvolveram quatro hipóteses relacionadas à emergência desse novo fenômeno, qual seja, a regulação ou governança privada:

1) A governança privada pode trazer resultados quando as cadeias são verticalizadas/coordenadas. Quanto mais as grandes empresas tiverem pequenos fornecedores em suas cadeias de valor e com isso, puderem alavancar o desenvolvimento destes fornecedores, será mais fácil monitorar o cumprimento das normas e critérios.

2) A governança privada exige um sistema de vigilância permanente para gerar incentivos positivos ao bom comportamento das empresas, isso significa que elas são mais vulneráveis a pressões sociais quando a demanda por um produto é construída por meio da identidade de marca do que em função da utilidade observada.

3) A governança privada é mais efetiva em razão da pressão social existente, a qual, por sua vez, depende da facilidade relativa de mobilização da ação coletiva. Isso significa que o arranjo institucional de cooperação da governança deve abarcar o conflito de interesses existente na produção de valor da cadeia.

4) A governança privada tende a ser adotada quando interesses comerciais se alinham com preocupações sociais ou ambientais.

Quando observamos a cadeia de valor global dos alimentos orgânicos, podemos concluir que ela permitiu a existência da governança privada e as duas últimas hipóteses desenvolvidas pelos autores, são essenciais para explicar a criação da IFOAM: a pressão social e o alinhamento de interesses comerciais às questões socioambientais. Como veremos mais adiante, a IFOAM surge muito ligada ao movimento social de produção de alimentos mais saudáveis e mais sustentáveis ambiental e socialmente. Com o aumento da demanda por estes alimentos nos países do Norte, produtores do Sul passam a adotar estes critérios na agricultura, o que exigiu a criação de um sistema de garantia de orgânicos. Neste sentido, a IFOAM passa a regular este mercado, por meio da acreditação das certificadoras que emitem selos e rotulagens que garantem o processo de produção mais sustentável, diminuindo, portanto, os custos de transação. O sistema de garantia via auditoria por terceira parte garante o enforcement de regras e o compliance dos produtores aderentes. Como resultado, há pouca assimetria nos resultados obtidos com a adesão às regras por parte de produtores de países em desenvolvimento, uma vez que eles buscam acessar estes mercados.

Apesar de não ser necessariamente uma atividade industrial, a produção de orgânicos certificada consegue coordenar as cadeias, tendo conhecimento da origem dos produtos e transparência de seus processos produtivos. Cashore (2002) nominou 
estas formas de regulação privada pelo mercado de Non-State Maket-Driven (NSMD) para explicar a razão da baixa assimetria da adesão às regras, a partir de suas principais características:

1.O sistema NSMD não procede de autoridades da soberania estatal. Mesmo com a participação estatal em alguns sistemas NSMD, isso não se faz como regra. Isso não significa que os Estados não são importantes na governança internacional, mas que, especificamente, nos casos de coordenação das cadeias produtivas, essa autoridade emerge do mercado, e de atores privados que captam os incentivos produzidos pelo sistema de produção.

2.As instituições NSMD se constituem como arenas de governança em que atores orientam-se propositivamente a objetivos coletivos e valores em que a adaptação, inclusão, e aprendizagem ocorrem ao longo do tempo e por meio de uma ampla gama de stakeholders, ou seja, é da diversidade normativa, manifestada por cada parte interessada que se chega ao aprendizado que fundamenta a cooperação para a implementação de regras.

3.A autoridade concedida ao sistema NSMD emana da cadeia de suprimentos do mercado, ou seja, é a rede que constrói o princípio da autoridade.

A maior contribuição de Cashore para a compreensão destes mecanismos de governança privada ocorre com o questionamento dos conceitos de legitimidade e autoridade que estes emanam. Parafraseando o autor:

A legitimidade política requer autoridades institucionalizadas (concentradas ou difusas) com recursos de poder para exercer as regras e também compartilhar as normas (princípios e critérios) entre a comunidade. As normas de legitimidade fornecem justificativas e uma compreensão compartilhada do que uma instituição aceitável ou apropriada deveria parecer e as fronteiras do que ela (instituição) pode e deve fazer ${ }^{3}$.

Ainda nas palavras de Cashore e Berstein (2007),

"Our framework focuses conceptual attention on how the normative environment and interactions of actors within NSMD communities determine and shape the process and content of legitimacy granting. This approach highlights that criteria of legitimacy are contingent on historical understandings at play and the shared norms of the particular community or communities granting authority".

Os autores ressaltam que a legitimidade é reforçada quando as normas e regras das organizações entram em conformidade com a estrutura social existente. As

\footnotetext{
${ }^{3}$ Tradução da autora
} 


\section{Governança transnacional para a regulação de alimentos orgânicos: $\mathrm{O}$ caso da IFOAM.}

pressões normativas da estrutura social global combinadas com o surgimento de normas comuns e de aprendizagem podem levar a uma redefinição de interesses diferentes e dos pré-requisitos para a construção generalizada de uma comunidade. No caso dos alimentos orgânicos, os boicotes e humilhações se dão em relação ao uso de transgênicos, agrotóxicos e fertilizantes industriais e a agricultura sustentável aparece como uma alternativa ao modelo vigente de produção de alimentos. Com o conhecimento das empresas que utilizam estas tecnologias, os consumidores mais conscientes passam a escolher produtos orgânicos certificados como garantia de não possuir estes insumos e garantir, desta forma, saúde e menor impacto socioambiental.

Neste sentido é que pode-se afirmar que existem diferenças entre a IFOAM e o FSC - Forest Stewardship Council - por exemplo. A primeira surge como federação de movimentos locais e nacionais de origem europeia, em 1972, com o intuito de impulsionar a produção e o consumo de alimentos orgânicos e, apenas na década de 1990 passa a regular mercado e credenciar as certificadoras. Já o FSC, o melhor exemplo de NSMD de acordo com o próprio Cashore, surge exatamente para coordenar a cadeia produtiva da madeira, alvo de inúmeras críticas dados os problemas socioambientais existentes nesta atividade produtiva e acreditar as certificadoras que estão de acordo com os princípios estabelecidos pela assembleia geral.

Voltando para o conceito de legitimidade política discutido por Cashore e Bernstein, ela se dá quando uma série de stakeholders se reconhecem como membros de uma comunidade política que garante um sistema NSMD com autoridade para governar. Os embates e as disputas continuam existindo, mas toda a comunidade reconhece o sistema como uma arena legítima que media estas disputas e resolve os problemas políticos. Assim, as estratégias não são mais criadas em relação à autoridade do sistema, mas sobre os processos e debates dentro de um sistema em que todos os participantes aceitam-no como legítimo. Os arranjos institucionais facilitam processos em que atores privados com e sem fins lucrativos participam juntos no desenvolvimento de padrões que melhor incentivam maneiras efetivas e eficientes para endereçar os problemas sociais e ambientais. Nesta questão, a IFOAM possui 870 membros entre associações de produtores, associações de consumidores, certificadoras, varejistas, distribuidores, entre outros que se entendem como membros de uma rede que possui autoridade para criar uma arena legítima de negociação e revisar os princípios, normas e formas de monitoramento da agricultura orgânica, assim como a atuação da própria rede. Entretanto, é possível questionar se o modelo de governança da IFOAM é de fato legítimo pelo fato de a maioria dos membros do Sul não participarem ativamente das assembleias gerais e os membros do Norte atuarem mais enfaticamente na elaboração dos princípios, uma vez que eles possuem grandes exigências sanitárias e barreiras comerciais e tarifárias. O próprio selo pode ser entendido neste caso como uma barreira. 
Cashore (2007), com base em duas abordagens teóricas - a teoria do advocacy coalitions framework que aborda os fóruns de aprendizagem política e a teoria habbermasiana, que por meio da ação comunicativa coloca a questão da justiça e do compartilhamento dos entendimentos - sugere algumas possibilidades para alcançar a legitimidade de fato. Para o autor, processos de aprendizagem que incluem fóruns para troca de experiências e informação, a construção de uma base de dados das experiências e das melhores práticas seria um caminho. Outro elemento importante é que os sistemas devem ser construídos para criar um ambiente de aprendizagem, no qual os stakeholders possam criar uma comunidade de compartilhamento dos entendimentos da legitimidade entre eles. $O$ valor de justiça também deve estar amplamente reconhecido entre os atores, mas depende menos dos procedimentos formais do que do senso de que os mais fracos possuem habilidade razoável para influenciar os resultados e que os mecanismos existem para garantir, a todos os atores, um senso de pertencimento na tomada de decisões que afeta a todos. Embora isso seja uma prioridade, colocar questões como transparência, acesso e senso de pertencimento entre players desempoderados, especialmente as empresas e grupos sociais do Sul, na prática, consubstamciam-se em enormes desafios.

A IFOAM, no meu entendimento, ainda não atingiu a legitimidade descrita por Cashore, pois, ainda não é consenso, pelo menos no Brasil, de que a agricultura orgânica possui um processo de produção mais sustentável, seja do ponto de vista da saúde, do meio-ambiente ou da sociedade. Para alcançá-la, ainda são necessárias campanhas de mobilização social, boicotes a indústrias alimentícias convencionais e informações sobre a produção de alimentos. O processo de aprendizagem que envolve todas essas variáveis ainda precisa ser construído. Além disso, não é do interesse de algumas empresas membro participarem efetivamente de uma comunidade de aprendizagem, construindo de fato um senso de pertencimento e igualdade entre os atores do Norte e do Sul. Ou elas são forçadas a participar pela questão da barreira comercial, ou simplesmente não há adesão. Isso fica ainda mais evidente quando se observa a existência de uma série de princípios da Agricultura Orgânica. Nos EUA, por exemplo, o Departamento de Agricultura, um órgão estatal, é o responsável pela certificação e pelo monitoramento dos princípios. No Brasil, com a promulgação da Lei 10.83103, estes princípios foram fixados e o MAPA - Ministério da Agricultura, Pecuária e Abastecimento não certifica, mas criou um selo que garante que o produto está de acordo com os seus princípios estipulados. O compliance neste caso é feito por coerção, pois todo produto orgânico deve conter o selo do governo. Assim, no Brasil, a IFOAM é mais um sistema de garantia, mas não o que cria os instrumentos de implementação dos princípios para o comércio local ou nacional, mas apenas para aqueles destinados à exportação.

Entretanto, pode-se perceber que o board da federação tem se dedicado a integrar os membros, discutir e votar as questões essenciais ao futuro da agricultura 


\section{Governança transnacional para a regulação de alimentos orgânicos: $O$ caso da IFOAM.}

orgânica e os seus sistemas de garantia, características extremamente importantes para a construção da legitimidade política.

\section{A Agricultura Orgânica - definição e histórico}

Para analisar a emergência da agricultura orgânica, faz-se necessária uma breve explicação sobre a história da agricultura moderna que surge nos séculos XVIII e XIX com a Primeira Revolução Agrícola, fase caracterizada pela intensificação dos sistemas rotacionais com forragens leguminosas e pela fusão das atividades agrícola e pecuária (EHLERS, 1999). Esse sistema propiciou aumentos na produção de alimentos e fibras em toda a Europa, garantindo a segurança alimentar da população neste período.

Ao longo do século XIX, com o advento da ciência iluminista e da indústria moderna, a agricultura foi incorporada por uma série de técnicas especializadas, como por exemplo, o emprego de energias fósseis e insumos industriais, como os fertilizantes químicos, agrotóxicos e motores de combustão interna, o que substituiu a rotação de culturas e distanciou a agricultura da pecuária. Esse novo modelo de produção agrícola formulou a segunda revolução da agricultura. (Idem)

Com a intensificação das técnicas utilizadas e o conseqüente aumento da produtividade, somados às mais novas descobertas científicas, surge a Revolução Verde que exporta para os países em desenvolvimento um "pacote" de técnicas a ser empreendido nas lavouras. Com isso, também se agravaram os problemas ambientais, a contaminação dos recursos naturais e dos alimentos, assim como a destruição dos habitats naturais.

Vale lembrar que a maioria dos países em desenvolvimento, como por exemplo, o Brasil possuía e possui até hoje um sistema agrícola pautado na grande propriedade e na monocultura, o que facilitou a assimilação das propostas da Revolução Verde. Outro fator crucial para a disseminação de tais preceitos agrícolas foi a criação de um enorme mercado de tratores e insumos químicos produzidos nos países já desenvolvidos.

Por outro lado, enquanto os representantes do mainstream da agricultura pesquisavam as técnicas que não consideravam os impactos negativos no meioambiente e na saúde, uma minoria de agricultores e pesquisadores ao redor do mundo valorizava a fertilização orgânica dos solos e o potencial biológico dos processos produtivos. Estes movimentos aconteceram na mesma época, entre as décadas de 192030, em diversos países como Alemanha (biodinâmico), Inglaterra e Índia (orgânico), Japão (natural) (EHLERS, 1999). Apesar de terem algumas pequenas diferenças conceituais, todas estas modalidades se encaixam no guarda-chuva da agricultura sustentável e procuram produzir seus alimentos sem a utilização de insumos químicos e industriais.

A agricultura alternativa começa então a ganhar força, já que aparece como um modelo capaz de alimentar as pessoas com saúde e com baixos impactos negativos ao meio-ambiente, gerando emprego e renda para as famílias do campo. 
Nessa mesma época, os problemas causados pela poluição da água e do ar, advinda dos processos industriais, trouxe às sociedades a preocupação com o meio em que elas vivem. De acordo com a abordagem construtivista, "a construção global das questões ambientais é tanto ou mais uma questão de construção social e política de conhecimento da produção, visto tratar-se de uma reflexão direta da realidade biofísica" (BUTTEL \& TAYLOR, 1992, apud HANNIGAN, 1995)

De acordo com o mesmo autor, na década de 70, a sociedade - principalmente dos países do Norte - começou a entender que a atuação do ser humano, como a produção e o consumo de bens e serviços, trazia conseqüências nem sempre positivas para o planeta, o que fez com que houvesse uma articulação geral para encontrar uma solução para tal. Não foi à toa que em 1972, ocorreu a primeira Conferência da ONU para discutir Desenvolvimento e Ambiente Humano, no mesmo ano em que surge a IFOAM para assegurar o futuro da agricultura orgânica ao redor do mundo. Para Maria Celia Souza (2006), a partir daí, o movimento da agricultura orgânica ganha força política, pois articula os produtores e certificadores a fim de legitimar ao mercado a procedência deste tipo de produtos.

\section{A Estrutura de Governança da IFOAM}

A IFOAM se caracteriza como uma organização privada, transnacional e multistakeholder que reúne 870 membros (entre grupos de agricultores, certificadores, varejistas e outros) de 120 países. De acordo com a própria organização, ela também se estrutura como uma rede, uma vez que possui braços externos à sua estrutura auto organizada. Sua missão é liderar, unir e apoiar o movimento da agricultura orgânica em sua plena diversidade. Seu objetivo é a adoção mundial de um sistema ecológico, social e econômico baseado nos princípios da Agricultura Orgânica. ${ }^{4}$

Ela possui um núcleo central sediado em Bonn, na Alemanha, responsável pela Assembleia Geral, pelos filiados, escritório e comitês; os Corpos Regionais que abarcam Agribio Mediterrâneo, Grupo União Europeia, Grupo América Latina e Caribe, França, Japão; as plataformas dos setores que incluem a Rede Intercontinental das Organizações de Agricultores Orgânicos, a Associação dos varejistas de orgânicos, o Grupo de Aquacultura e o Fórum de Comércio de Orgânicos. Além disso, hás as "organizações filhas": Serviços Internacionais de Acreditação de Orgânicos (IOAS) e a Fundação Mundo Orgânico. Abaixo uma figura que descreve bem o grupo de ação da IFOAM.

\section{Gráfico 3. Grupo de ação e rede IFOAM}

\footnotetext{
${ }^{4}$ Todas estas informações estão disponíveis no site < www.ifoam.org> e também no último relatório de atividades do ano de 2011, que pode ser encontrado no mesmo website. Último acesso em 15/08/2012.
} 


\section{IFOAM's ACTION GROUP AND ITS NETWORK}

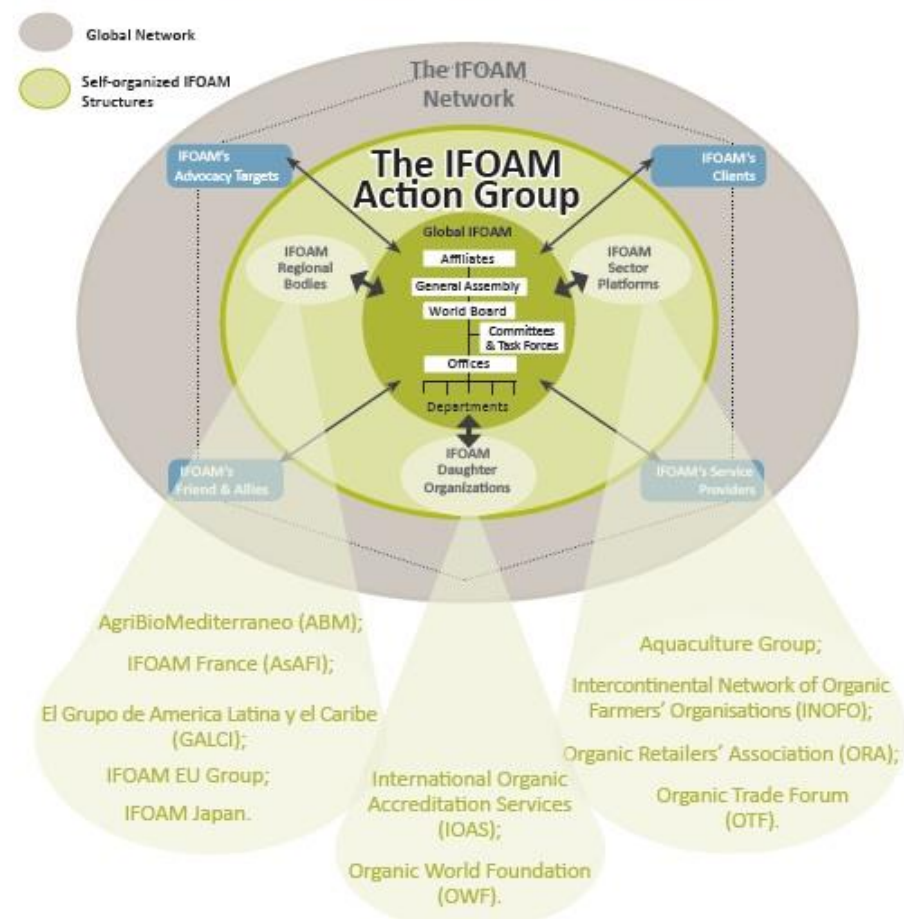

Fonte: Relatório de atividades de 2011 da organização. Disponível em $<$ http://ifoam.org/public/Annual\%20Report/IFOAM_Annual_Report_2011_web.pdf>; último acesso em 2408/2012.

Seu processo de governança pode ser comparado a um "quase governo", quando pensado na estrutura deliberativa, uma vez que possui princípios, critérios e indicadores claros e processos decisórios que exigem que os membros se reúnam com frequência. Além disso, as partes interessadas possuem voz e voto para decidir os rumos da organização. A sua criação está ligada à necessidade de se ter informação e garantia do processo de produção da agricultura orgânica, o que exigiu selos e certificados para que o consumidor pudesse ter certeza de que o produto que escolheu respeita os direitos trabalhistas, não utiliza insumos químicos e tampouco, organismos geneticamente modificados. O certificado também permite ao produtor um prêmio nos preços dos bens por produzir com maior responsabilidade socioambiental ${ }^{5}$, construindo dessa forma um mercado que incorpora questões sociais e ambientais, para utilizar a expressão de Mark Granovetter.

\footnotetext{
${ }^{5}$ Tradução feita pela autora.
} 
De acordo com seu relatório de atividades, ao liderar os movimentos dos alimentos orgânicos em todo o mundo, desde 1972, a IFOAM implementa a vontade de seu eleitorado de base ampla - de organizações de agricultores às agências de certificação multinacionais, garantindo a credibilidade e longevidade da Agricultura Orgânica como um meio para a sustentabilidade ecológica, econômica e social. (...) Por meio de conferências internacionais, reuniões de comissões e outros fóruns, a IFOAM facilita o diálogo permanente e construtivo sobre o seu futuro estatuto e da agricultura orgânica. A organização também ajuda seus membros a implementar projetos específicos que facilitem a adoção da agricultura orgânica, particularmente nos países em desenvolvimento. A IFOAM também representa os movimentos de agricultura orgânica na Organização das Nações Unidas e outras agências intergovernamentais por meio do seu programa de advocacy.

É possível perceber, desta forma, a complexidade de atividades, atores e embates que esta organização possui e, ao mesmo tempo, que ela se enquadra na categoria de organização transnacional privada. Estudá-la empiricamente e aprofundar o conhecimento sobre este tipo de instituição pode trazer um enriquecimento à teoria das instituições, assim como das Relações Internacionais e seus novos atores.

\section{Conclusões}

O crescimento do mercado de alimentos orgânicos em nível global fez com que houvesse a criação de uma organização que regulasse a produção, por meio da elaboração de critérios, princípios e indicadores cristalizados em selos e certificações que garantem que tal produto é, de fato, orgânico. Esta organização chamada IFOAM é responsável por unir e apoiar o movimento da agricultura orgânica mundialmente, seja por meio da garantia de certificação, seja por atividades de advocacy em políticas públicas via Nações Unidas. O artigo se debruçou sobre os desafios de compliance e enforcement que tal organização possui em relação a seus membros. Percebe-se que ela possui um amplo reconhecimento, uma vez que reúne membros de 120 países diferentes. Esses membros agem de acordo com as normas colocadas pela IFOAM, ou seja, há compliance, pois a família de standards é discutida e aprimorada com a participação de todos os membros, no processo da Assembleia Geral. Este conjunto de princípios são as normas que devem ser seguidas e elas são representadas pelos selos. O grande gargalo é que existem vários conjuntos de standards para orgânicos ao redor do mundo e todos os "donos" dos standards demandam compliance de seu próprio sistema e não estão prontos para aceitar outros padrões como equivalentes.

O enforcement se dá por conta do comércio internacional. Para acessar os mercados da Europa e EUA é necessário estar de acordo com as normas da IFOAM e USDA, respectivamente. O Codex Alimentarius e o ISO 65 também devem ser respeitados. Assim, a IFOAM consegue enforçar os seus princípios por conta das barreiras comerciais que exigem que os alimentos orgânicos sejam produzidos de acordo com os princípios pré-estabelecidos. 


\section{Governança transnacional para a regulação de alimentos orgânicos: $\mathrm{O}$ caso da IFOAM.}

No Brasil, a partir de 2011, todos os produtos orgânicos tem que ser obrigatoriamente certificados, com exceção de venda direta ao consumidor e devem respeitar a Lei $10831 / 03$ que possui diferenças em relação ao princípio privado.

É possível perceber também que, devido ao histórico e às questões comerciais da própria estrutura do sistema, existem assimetrias de poder dentro da governança da federação. Apesar destas assimetrias não estarem presentes nos selos e nos processos de certificação, é relatado pela própria organização que os membros dos países do Sul passaram a participar ativamente das Assembleias Gerais em 2008. Essa questão se dá devido à configuração do mercado, em que os membros dos países do Sul se apresentam como produtores e membros dos países do Norte como consumidores. Percebe-se, portanto, que os atores possuem posições diferentes na tomada de decisão, construindo assim, papéis diferentes dentro da rede, fato que exige uma avaliação mais apurada.

Com uma clara posição normativa, acredito que a IFOAM possa vir a se tornar politicamente legítima perante os membros de todos os seus países à medida que a agricultura orgânica se configurar como uma possibilidade para todos os consumidores e produtores e à medida que os atores possuírem mais igualdade no papel que desempenham dentro da organização.

\section{Referências}

BERSTEIN, B. Legitimacy and the privatization of Environmental Governance: How NSMD Governance System Gain Rule Making Authority; Governance: an international journal of Policy, Administration and Institutions; 2002, Blackwell Publishing: Oxford.

BERSTEIN, S; CASHORE, B; Can non-state global governance be legitimate? An analytical framework; Journal compilation; 2007 Blackwell Publishing Asia Pty Ltd.

EHLERS, Eduardo. Agricultura sustentável - origens e perspectivas de um novo paradigma. Guaíba: Agropecuária, 1999

FONSECA, Maria F. "A institucionalização dos mercados de orgânicos no mundo e no Brasil: uma interpretação". Tese de doutorado em Sociologia, UFRuralRJ, CPDA, Rio de Janeiro: 2005.

GRANOVETTER, Mark. "Ação econômica e estrutura social: o problema da imersão". RAE Eletrônica - Fundação Getúlio Vargas, São Paulo, 1 (6), janeiro / julho, 2007. 
HALE, T; HELD; D. Handbook of Transnational Governance, 2011 Cambridge Press.

HANNIGAN, John. Sociologia Ambiental. Lisboa: Stória Editores: 1995 (Trad. Clara Fonseca)

IFOAM, Annual Report. Bonn: 2011. Disponível em

<http://ifoam.org/public/Annual\%20Report/IFOAM_Annual_Report_2011_web.pdf>; último acesso em 2408/2012.

IFOAM. "Normas de IFOAM para la producción y el procesamiento orgánicos", Bonn: 2009. Disponível em ‘www.ifoam.org〉. Acesso em 20/09/2011.

MAYER, F; GEREFFI; G; Regulation and Economic Globalization: Prospects and Limits of Private Governance; Volume 12, 2010 Business and Politics; Berkeley Electronic Press.

RAYNOLDS, L. The Globalization of Organic Agro-Food Networks. World Development Vol. 32, No. 5, 2004; Elsevier.

RISSE KAPEN; Bringing transnational relations back in; Non-state actors, domestic structures and international institutions, 2003, Cambridge Press. 